\title{
Effective factors on optimizing banks' balance sheet using fuzzy analytical hierarchy process
}

\author{
Shoja Rezaei ${ }^{\text {a* }}$, Kianoush Nazari Ameleh ${ }^{\mathrm{b}}$, Ali Ramezanzadeh ${ }^{\mathrm{c}}$, Mohammad Hassan Nasrabadi ${ }^{\mathrm{d}}$ \\ and Behnam Rezaei ${ }^{\mathrm{e}}$
}

${ }^{a}$ Master of Business Management, Department of Management, Tehran University, Tehran, Iran

${ }^{b}$ Department of Business Management, Science and Research Branch, Islamic Azad University, Tehran, Iran

${ }^{c}$ Master of Business Management, Department of Accounting \& Management, Allameh Tabataba'i University, Tehran, Iran

${ }^{d}$ Department of Business Management, Science and Research Branch, Islamic Azad University, Tehran, Iran

${ }^{e}$ Master of Business Management, Department of Accounting \& Management, Allameh Tabataba'i University, Tehran, Iran

C H R ON I C L E

Article history:

Received June 22, 2013

Received in revised format

28 August 2013

Accepted 27 September 2013

Available online

September 302013

Keywords:

Fuzzy analytical hierarchy process (FAHP)

Balance sheet

Asset

Liability

Paired comparison

Refah Bank

\section{A B S T R A C T}

\begin{abstract}
Every bank seeks methods to optimize its assets and liabilities, thus the main subject is managing assets-liabilities in the balance sheet and the main question is by which factor banks will be enabled to have an optimized combination of assets and liabilities in a common level of risk to get the most return. This case study is dedicated to Refah bank and is an applicable study. The data has collected from the headquarter by a questionnaire and finally effective factors weight on optimizing bank balance sheet determined by using Fuzzy analytical hierarchy process. Results showed that revenue has more effect on optimizing for $\% 39.5$ and also loan to deposit ratio for \%.74, regarding revenue as a symbol of efficiency in banks, it seems to be the most important factor and goal in banking industry. Furthermore banks need to have some liquidity to respond customers demand to cover one of the most important risks of banking. This factor importance determined to be \%18 in Refah Bank by using model and experts view.
\end{abstract}

(C) 2013 Growing Science Ltd. All rights reserved.

\section{Introduction}

In an economy banks are financial entities that collect stagnant and useless moneys from where there is surplus resources and injecting it into where there is insufficient amount of cash flow and investment. On the other hand banks play as mediators between organizations and people with surplus in liquidity and the others with shortage. Any problem in banking system influences every beneficiary and the whole economy (Secme et al. 2009) and some banks have moved towards none financial measures. Husain et al. (2002) defined these factors as competitive pressures, economic and technological progress, political, economic and social circumstances, business culture and top management (Husain \& Gunasekaran, 2002). Financial measures have significance role on

*Corresponding author. Tel: +98 933749907

E-mail address: rezaeishoja@yahoo.com (S. Rezaei) 
optimization of financial structure, which can be defined as: number of products and services sold in terms of revenue, operational revenue and net profit and these measures do not seem to be enough to create a strategic program and policy (Thevaranjan et al 1999). The primary objective is to manage asset-liability in the balance sheet and determine which factors optimize combination of assets and liabilities in a common level of risk. This need cause banks to determine optimized level of profitability, risk, liquidity and other resources of uncertainty. These determinations are some of the most important issues that most banks managers are dealing with. These subjects along with new regulations and competition have increased the relative importance to asset-liability management in recent years (Gerstner et al., 2008). Thus, there are some attempts to determine effective factors on balance sheet by quantitative model of fuzzy analytical hierarchy process (FAHP) (Wang \& Chin, 2011). In a system like banking where decision making includes several input and outputs, all criteria that have effect on optimization must be integrated and considered at once (Li et al., 2001). To do this we chose FAHP method to investigate that will be considered in the following. For involving in fuzzy issues and its meanings, Saaty considers analytical hierarchy process as an appropriate technique that measures fuzzy ratio by a layer structure in the form of paired comparison. AHP and its application are based on 3 principals;
A. Making a layer structure for the problem
B. Ranking by paired comparison
C. Establishing logical consistency (Alemtabriz \& Bagherzade, 2008)

\section{Materials and Methods}

\subsection{Fuzzy Analytical Hierarchy Process}

In 1983 two Switzerland scholars, Laarhoren and Padrycz recommended a process for FAHP, which was based on Logarithmic least squares method. The complexity of this method cause it failed to develop. In 1996 another method in the name of Extent Analysis (EA) method was presented by a Chinese scholar; Chang and triangular fuzzy numbers were used in this method. In the following the EA concepts and definitions will be introduced (Azar \& Faraji, 2007). The first step in FAHP is to define alternatives by using important criteria and options. Often mentioned hierarchy is made from main goals (first level), assessing criteria (middle level) to alternatives (Jung Hosing, 2011).

\subsection{Factors Effective on Balance Sheet Structure}

There are many factors influencing on banks' balance sheets and the effect of each one is different. Regarding this fact and using banking expert's viewpoint we gathered variables that have most effect on. As a fact it must be acknowledged that the numbers come in following sections about each variable is that of central bank or banks own numbers that managers must achieve.

1. Revenues: banks revenue is a sign of efficiency and also as a criterion of measuring macroeconomic policies effects on bank. Main bank resource is profit from loans, revenues from bonds, commissions especially from letter of guarantee. Bank major expenditures are deposit interest. This interest is different for each year regarding loans profit. Cost of doubtful receivables is considered reserved \% 1.5 of loan remaining, announced by central bank 2006.

2. Capital adequacy: Capital is an important pillar of the Bank's funding, which allows the bank to meet its debt repayment ability is difficult macroeconomic situations. Nowadays for assessing banks and financial entities there are some indexes that of which capital adequacy ratio is very important. For the first time in 1988 this ratio was introduced to banks by Basel Committee on

Banking Supervision based in Bal city, Swiss (18). The ratio is $\% 8$ for Iranian banks and calculate as follows,

$\frac{\text { Capital Ratio }}{(\text { Risk ratio })\left(\begin{array}{c}\text { Conversion } \\ \text { Coefficient }\end{array}\right)\left(\begin{array}{c}\text { Bottomline } \\ \text { items }\end{array}\right)+\left(\begin{array}{c}\text { Risk } \\ \text { Coefficient }\end{array}\right)\left(\begin{array}{c}\text { Topline } \\ \text { items }\end{array}\right)}$


3. Loan to Deposit Ratio: it shows the efficiency of applying banks resources and is considered as $\% 85$ of banks resources.

4. Liquidity: according to bank procedures $\% 1.5$ of banks deposits is dedicated to cash money or high liquidity assets.

5. Assets Growth: the assets growth, deposits and loans of successful banks are higher than industry average that reflex aggressive management or popularity of services in the eyes of customers. Anyway growth must not be replaced by profit. If the growth not be on the accurate study and be out of control, it will cause more operational expenses than revenues. A growth is favorable when create economic value added.

6. Fixed Assets: it is a kind of assets that does not create direct revenues and is a kind of long term investment. According to banking laws and regulation $\% 30$ of equity must be dedicated to these types of assets.

\subsection{Structure of Analytical Hierarchy Process Model}

For ease of using analytical hierarchy process, the case decomposed into several levels that show goals, criteria and alternatives. Six decision making criteria are Revenue, Capital Adequacy Ratio, loan to Deposit Ratio, Liquidity, Fixed Assets and Assets Growth. In the alternatives section each of above items are compared to measure priority.

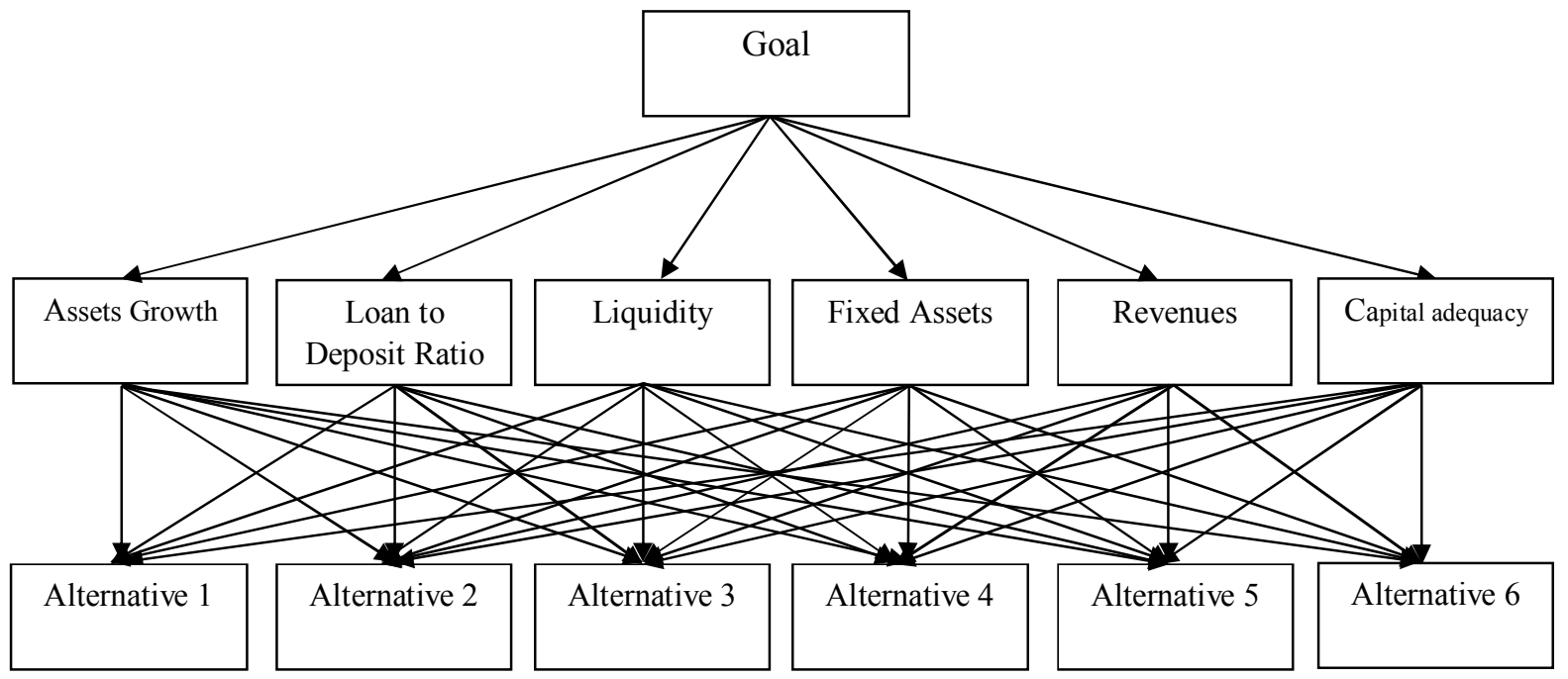

Fig. 1. Structure of Analytical Hierarchy Process Model in This Study

According to Saaty (1980), AHP is a method for decision making aimed coordinating decision maker view in solving complex problems. Using this systematic method problem we may divide a system into layers, which makes assessing easier. Decision maker must decide between the two factors to judge the importance of each factor. Buckley (1985) also used this model in his research. In first step he acquired each expert's opinion for each of the decision criteria and then prioritized as alternatives (Buckley, 1985). Buckley et al. (2001) found that decision makers show relative importance of the two criteria using fuzzy smooth or trapezoidal numbers to be able to create fuzzy positive reciprocal matrix. Thus, the geometric average used to calculate the fuzzy weights in matrix (Buckleyet al., 2001). Che et al. (2010) also used fuzzy AHP and Data Envelopment Analysis (DEA) approach for making decisions on small and medium-sized company's lending from banks. They used FAHP to choose important criteria in assessing each lending (Che, et al., 2010). Jung (2011) used combined approach of FAHP and Goal programming in a continuous production planning, considering manufacturing partners. Using FAHP, they determined relative weights of manufacturing partners that could help in productive capacity, then by goal programming model they measured internal and 
external usage capacity. In Iran, many scholars used AHP method in many fields. Karimi (2006) used AHP in an evaluation of Karafarin Bank. In this study, capital adequacy, investments, liquidity, assets growth, deposits and fixed assets were considered as banks goals. She suggested conservative policies for liquidity and asserts that capital adequacy and liquidity risks were in an appropriate condition. However, paired comparison between investment ratio and deposits with capital adequacy was missed by scholar, while capital adequacy was one of the balance sheet and banking principals. Ketabi et al. (2008) selected the best spare part supplier in their study entitled using FAHP.

\section{Research Methodology}

In current study we look for the most effective factors on bank's balance sheet. Thus, a questionnaire based on AHP principals was distributed among financial bureau expert members and their viewpoints were gathered. Then the outputs put into Paired Comparison Matrixes that indicates each items relative importance. The study is an applicable study and presents results to banks managers for using. Finally from 40 distributed questionnaires, 33 were usable (\%82.5 respond rates) and were calculated by 33 matrixes. All results are placed in a matrix that shows each factors importance.

\section{Findings}

\subsection{Paired Comparison Matrix}

As mentioned before, each expert's viewpoint is considered in a matrix and consistency rate of each matrix is calculated separately to be used for final matrix. In Table 1 a correspondent matrix and its calculation is illustrated.

\section{Table 1}

Paired Comparison, Correspondent (i)

\begin{tabular}{|c|c|c|c|c|c|c|}
\hline Revenue & 1 & 5 & 7 & 5 & 7 & 7 \\
\hline Capital Adequacy Ratio & & 1 & 1 & $1 / 3$ & 3 & $1 / 3$ \\
\hline Loan to Deposit Ratio & & & 1 & 3 & 3 & $1 / 3$ \\
\hline Liquidity & & & & 1 & 1 & 3 \\
\hline Fixed Assets & & & & & 1 & 3 \\
\hline Assets Growth & & & & & & 1 \\
\hline
\end{tabular}

This matrix represents the correspondent (i) viewpoint about each criteria, for example number 5 in second column of first row indicates that revenue impact and priority is more important (regarding to options; Equal, relatively more important, more important, very important, Extremely important) than capital adequacy ratio. It should be noted that the reverse numbers corresponding to each pair number has omitted. Table 2 is a combination matrix of 11 correspondent's viewpoint

Table 2

Matrix of Paired Comparison, Correspondent (i)

\begin{tabular}{llllllllllllllllll}
\hline 1 & 1 & 1 & 4 & 5 & 6 & 6 & 7 & 8 & 4 & 5 & 6 & 6 & 7 & 8 & 6 & 7 & 8 \\
\hline 0.167 & 0.2 & 0.25 & 1 & 1 & 1 & 1 & 1 & 1 & 0.25 & 0.333 & 0.5 & 2 & 3 & 4 & 0.25 & 0.333 & 0.5 \\
0.125 & 0.143 & 0.167 & 1 & 1 & 1 & 1 & 1 & 1 & 2 & 3 & 4 & 2 & 3 & 4 & 0.25 & 0.333 & 0.5 \\
0.167 & 0.2 & 0.25 & 2 & 3 & 4 & 0.25 & 0.333 & 0.5 & 1 & 1 & 1 & 1 & 1 & 1 & 2 & 3 & 4 \\
0.125 & 0.143 & 0.167 & 0.25 & 0.333 & 0.5 & 0.25 & 0.333 & 0.5 & 1 & 1 & 1 & 1 & 1 & 1 & 2 & 3 & 4 \\
0.125 & 0.143 & 0.167 & 2 & 3 & 4 & 2 & 3 & 4 & 0.25 & 0.333 & 0.5 & 0.25 & 0.333 & 0.5 & 1 & 1 & 1 \\
\hline
\end{tabular}

After collecting paired wise comparison data (Table 1) and calculating by Expert Choice, we have matrix of Table 2. The consistency rate of this matrix is 0.2073 , which is acceptable. Other 10 matrixes also are calculated by the same method to reach the final one. Table 3 is the final matrix of paired comparison of goals priorities and from the correspondent's viewpoint have the most effect on optimizing goal function. 
Table 3

Matrix of Paired Comparison of Goals

\begin{tabular}{|c|c|c|c|c|c|c|c|c|c|c|c|c|c|c|c|c|c|}
\hline $\mathrm{C} 1$ & & & $\mathrm{C} 2$ & & & $\mathrm{C} 3$ & & & $\mathrm{C} 4$ & & & $\mathrm{C} 5$ & & & C6 & & \\
\hline 1 & 1 & 1 & 2.629 & 3.1473 & 3.6982 & 2.9821 & 3.6432 & 4.3524 & 1.3208 & 1.6489 & 2.0433 & 4.5158 & 5.5619 & 6.5907 & 4.24 & 5.3095 & 6.3522 \\
\hline 0.2704 & 0.3177 & 0.3804 & 1 & 1 & 1 & 3.1088 & 3.6124 & 3.9623 & 0.6958 & 0.7818 & 0.8911 & 2.4422 & 3.0739 & 3.738 & 1.7177 & 2.2094 & 2.8 \\
\hline 0.2298 & 0.2745 & 0.3353 & 0.2524 & 0.2768 & 0.3217 & 1 & 1 & 1 & 0.3804 & 0.4741 & 0.604 & 0.722 & 0.9546 & 1.2535 & 0.5408 & 0.6754 & 0.8588 \\
\hline 0.4894 & 0.6065 & 0.7571 & 1.1222 & 1.2791 & 1.4371 & 1.6555 & 2.1092 & 2.629 & 1 & 1 & 1 & 1.3208 & 1.6105 & 1.8981 & 1.4067 & 1.8773 & 2.3538 \\
\hline 0.1517 & 0.1798 & 0.2214 & 0.2675 & 0.3253 & 0.4095 & 0.7978 & 1.0475 & 1.3851 & 0.5268 & 0.6209 & 0.7571 & 1 & 1 & 1 & 0.5822 & 0.6702 & 0.7689 \\
\hline 0.1574 & 0.1883 & 0.2358 & 0.3571 & 0.4526 & 0.5822 & 1.1644 & 1.4807 & 1.8491 & 0.4248 & 0.5327 & 0.7109 & 1.3005 & 1.4922 & 1.7177 & 1 & 1 & 1 \\
\hline
\end{tabular}

After building matrix and prioritizing criteria, mean value of viewpoints must be calculated to get the mean significance of each criterion.

\section{Table 4}

Mean value of Combined Fuzzy Triangular of Expert's Viewpoint

\begin{tabular}{llllll}
\hline 1 & 3.1473 & 3.6432 & 1.6489 & 5.5619 & 5.3095 \\
0.3177 & 1 & 3.6124 & 0.7818 & 3.0739 & 2.2094 \\
0.2745 & 0.2768 & 1 & 0.4741 & 0.9546 & 0.6754 \\
0.6065 & 1.2791 & 2.1092 & 1 & 1.6105 & 1.8773 \\
0.1798 & 0.3253 & 1.0475 & 0.6209 & 1 & 0.6702 \\
0.1883 & 0.4526 & 1.4807 & 0.5327 & 1.4922 & 1 \\
\hline
\end{tabular}

One of the reasons that AHP has superiority to other multi-criteria decision making methods is that enables us to calculate consistency rate. Consistency is a mechanism that ensures the reliability of comparisons made by group. If the rate is Less than or equal to 0.10 the comparisons consistency is acceptable (Saaty, 1980).

Table 5

Consistency Rate

\begin{tabular}{lllll}
\hline$\lambda_{\max }$ & CI & CR & RI \\
\hline 6.1591 & 0.0318 & 0.0255 & 1.24 & \\
\hline
\end{tabular}

Table 6 summarizes the final rank of criteria, which helps us optimize the goal function of bank. This matrix has gone through several normalizing process like right and left number normalizing, absolute normalizing and normalized weights.

Table 6

The summary of ranking each factor for optimizing bank balance sheet

\begin{tabular}{|c|c|c|c|c|c|c|c|c|}
\hline & & & & & & & Weight & Rank \\
\hline Revenues & 1 & 3.157 & 3.649 & 1.67 & 5.485 & 5.238 & 0.395 & 1 \\
\hline Capital Adequacy Ratio & 0.319 & 1 & 3.575 & 0.785 & 3.086 & 2.243 & 0.186 & 2 \\
\hline Loan to Deposit Ratio & 0.275 & 0.278 & 1 & 0.478 & 0.97 & 0.683 & 0.074 & 6 \\
\hline Liquidity & 0.611 & 1.282 & 2.134 & 1 & 1.616 & 1.892 & 0.18 & 3 \\
\hline Fixed Assets & 0.18 & 0.327 & 1.068 & 0.626 & 1 & 0.672 & 0.074 & 5 \\
\hline Assets Growth & 0.189 & 0.456 & 1.499 & 0.54 & 1.502 & 1 & 0.092 & 4 \\
\hline
\end{tabular}

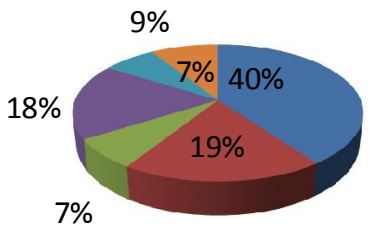

$\square$ Revenues $\square$ Capital Adequacy Ratio $\square$ Loan to Deposit Ratio $\square$ Liquidity $\square$ Fixed Assets $\square$ Assets Growth

Fig. 2. Final Weight of Each Criterion 


\section{Discussion and Conclusion}

The results of this study are consistent with other studies since Buckley et al. (2001). Che et al. (2010) also used fuzzy AHP and Data Envelopment Analysis (DEA) approach for making decisions on small and medium-sized company's lending from banks. They used FAHP to choose important criteria in assessing each lending. Jung (2011) used combined approach of FAHP and goal programming in a continuous production planning. Banks and non-bank financial institutions are looking more efficient ways of using their resources. In this case, restrictions and obligations of a country's banking system and economy must be observed. Reaching a level of profitability with a common level of risk and also recognizing goal and related criteria are of competitive factors for this type of companies. There are criteria recognized by bankers but the impacts that these factors have on optimizing of balance sheet and other financial statements are not well recognized by bankers. We believe it is the importance of each criteria and goal that correspondents determined. Of this criteria revenue has the most impact, \%39.5 comparing to loan to deposit ratio \% 0.074 . Regarding Revenue importance it must be set as the main objective of the bank, also bank must hold adequate amount of liquidity to address customer's demands and to control liquidity risk, this criteria with a value of $\%$ 18 stands in the third place and other criteria also must be treated, accordingly.

\section{References}

Alemtabriz, A., \& Bagherzade A. M. (2008). Assessment of the quality control system structure using link model (Analytical Hierarchy Process - goal programming) [In Persian].

Azar, A., \& Faraji, H. (2007). Fuzzy Science Management, Mehraban pub, Tehran [In Persian].

Basel Committee on Banking Supervision (2002). Consultative Documents of the Basel Committee on Banking Supervision, the Basel New Capital Accord.

Buckley, J. J. (1985). The multiple judge multiple criteria ranking problem: A fuzzy set approach. Fuzzy Sets and Systems, 13, 25-37.

Buckley, J. J., Feuring, T., \& Hayashi, Y. (2001). Theory and methodology: Fuzzy. Hierarchical analysis revisited. European Journal of Operational Research, 129, 48-64.

Che, Z., Wang, H. S., \& Chuang, C. L. (2010). A fuzzy AHP and DEA approach for making bank loan decisions for small and medium enterprises in Taiwan. Expert Systems with Applications, 37(10), 71897199.

Gerstner, T., Griebel, M., Holtz, M., Goschnick, R., \& Haep, M. (2008). A general asset-liability management model for the efficient simulation of portfolios of life insurance policies. Insurance: Mathematics and Economics,42(2), 704-716.

Ghodsipour, S. H. (2006). Analytical hierarchy Process, Amirkabir University Pub, Tehran.

Hussain, M. \& Gunasekaran, A. (2002). An institutional perspective of non-financial management accounting measures: A review of the financial services industry. Managerial Auditing Journal, 17(9), 518-536.

Jung, H. (2011). A fuzzy AHP-GP approach for integrated production-planning considering manufacturing partners. Expert systems with Applications, 38(5), 5833-5840.

Karimi, M. (2006). Optimizing bank assets \& liabilities by AHP and goal programming. (Case study: Karafarin Bank, (Master's thesis).

Ketabi, S., Haghshenas, A. \& Hadadian, A. (2008). Multi-Criteria selection of suppliers using FAHP. Islamic Center of Computer Sciences.

Kosmidou, K., \& Zopounidis, C. (2004). Combining goal programming model with simulation analysis for bank asset liability management. INFOR, 42(3), 175-187.

Li, S., Liu, F., Liu, S., \& Whitmore, G. A. (2001).Comparative performance of Chinese commercial banks, findings and policy implications, Reviews of Quantities Finance and Accounting, 16,149-170.

Saaty, T. L. (1980). The analytic hierarchy process. McGraw-Hill

Secme, N. Bayrakdaroglu, A., \& Kahraman, C. (2009). Fuzzy performance evaluation in Turkish Banking Sector using Analytic Hierarchy Process and TOPSIS. Expert Systems with Applications, 36, 11699-11709

Thevaranjan, A., Joseph, K., \& Srinivasan, D. (1999). Managerial myopia and non financial measures: The case of customer satisfaction mitigating hard-selling. Managerial Accounting Research Conference, Orlando.

Wang, Y. M., \& Chin, K. S. (2011). Fuzzy analytic hierarchy process: A logarithmic fuzzy preference programming methodology. International Journal of Approximate Reasoning, 52(4), 541-553. 